\title{
Ice deformation very close to the ice-sheet margin in West Greenland
}

\author{
Peter G. KNIGHT \\ Department of Geography, Keele University, Keele, Staffordshire ST5 5BG, England
}

\begin{abstract}
This paper describes fine-resolution measurements of glacier surface strain rates very close to the margin of Russell Glacier, West Greenland. Measurements at a small scale make possible detailed analysis of strain patterns close to the glacier margin, and suggest that strain rates vary over small areas. The strain pattern is determined by ice flexure over subglacial obstacles as well as by seasonally variable marginal retardation and by the orientation of the ice margin relative to the flow direction.
\end{abstract}

\section{INTRODUCTION}

This paper describes the detailed strain environment very close to the margin of an outlet glacier of the Greenland ice sheet and relates this strain environment to topographic and climatic conditions at the ice margin. Previous work, involving measurement and modelling of ice flow and deformation, has commonly neglected the glacier margin, but flow conditions and deformation at the margin are important both for the dynamics of the glacier as a whole and for glacial geomorphology. The distribution of englacial debris close to the margin and the style of its evacuation from the ice depend on the nature of ice flow and deformation at the margin so, if detailed strain characteristics at the margin can be correlated with specific depositional environments, land forms of glacial deposition can be more effectively interpreted and used as reconstructive tools in formerly glaciated areas.

Several methods of determining surface strain rates by observing the deformation of arrays of markers on the glacier surface have been described in the literature (e.g. Nye, 1959; Meier, 1960; Hambrey and Müller, 1978; MacAyeal, 1985). These methods define an area on the glacier surface and observe its changing shape over time. The resulting measures of strain and strain rate are average values for the whole of the defined area. Most commonly, the smallest strain areas used in published strain analyses have been of the order of $100-1000 \mathrm{~m}^{2}$, defined by triangles with sides between 15 and $50 \mathrm{~m}$ in length. In this paper, much smaller strain areas of the order of $1-10 \mathrm{~m}^{2}$ are also used, defined by triangles with sides between 2 and $5 \mathrm{~m}$. This makes it possible to test assumptions of strain homogeneity across the larger areas, and to identify changes in strain patterns over very small distances very close to the glacier margin.

The method of measuring surface strain used here follows Hambrey and Müller (1978), and determines the magnitude and orientation of principal strains from measurements of triangular marker arrays by using a Mohr-circle analysis. Glaciological applications of this method (e.g. Hambrey and Müller, 1978; Hambrey and others, 1980; Gemmell, 1985) have hitherto drawn on Ramsay's (1967) geological description of the procedure, but the data resolution which Ramsay described involves a combination of calculation and graphical analysis which is time-consuming, imprecise relative to field measurements and prone to error. For the present analysis, Ramsay's procedure was converted to a purely numerical form and thence into a user-friendly computer program, details of which have been given by Williams and Knight (1987 a, b). The input data for the calculations are the distances between the markers on the glacier surface at an initial time and at subsequent times. The outputs are the change in surface area and the orientation and magnitude of the principal compressive, extending and shear strain rates.

What is lacking from the present data is an error analysis demonstrating the exact level of significance of the results. Especially for small-area measurements over short time-scale, there is potential for some errors in the measurement of strain rates. Although these can be minimized by careful design of the experimental programme (MacAyeal, 1985) and by ensuring that measured displacements within the stake network well exceed the measurement error of the surveying equipment and procedure, a more complete justification of the use of such small-area and short-time measurements would require a clear demonstration of the levels of possible error.

\section{THE STUDY AREA}

These measurements were carried out on the snout of Russell Glacier, West Greenland (Fig. 1). The glacier is 


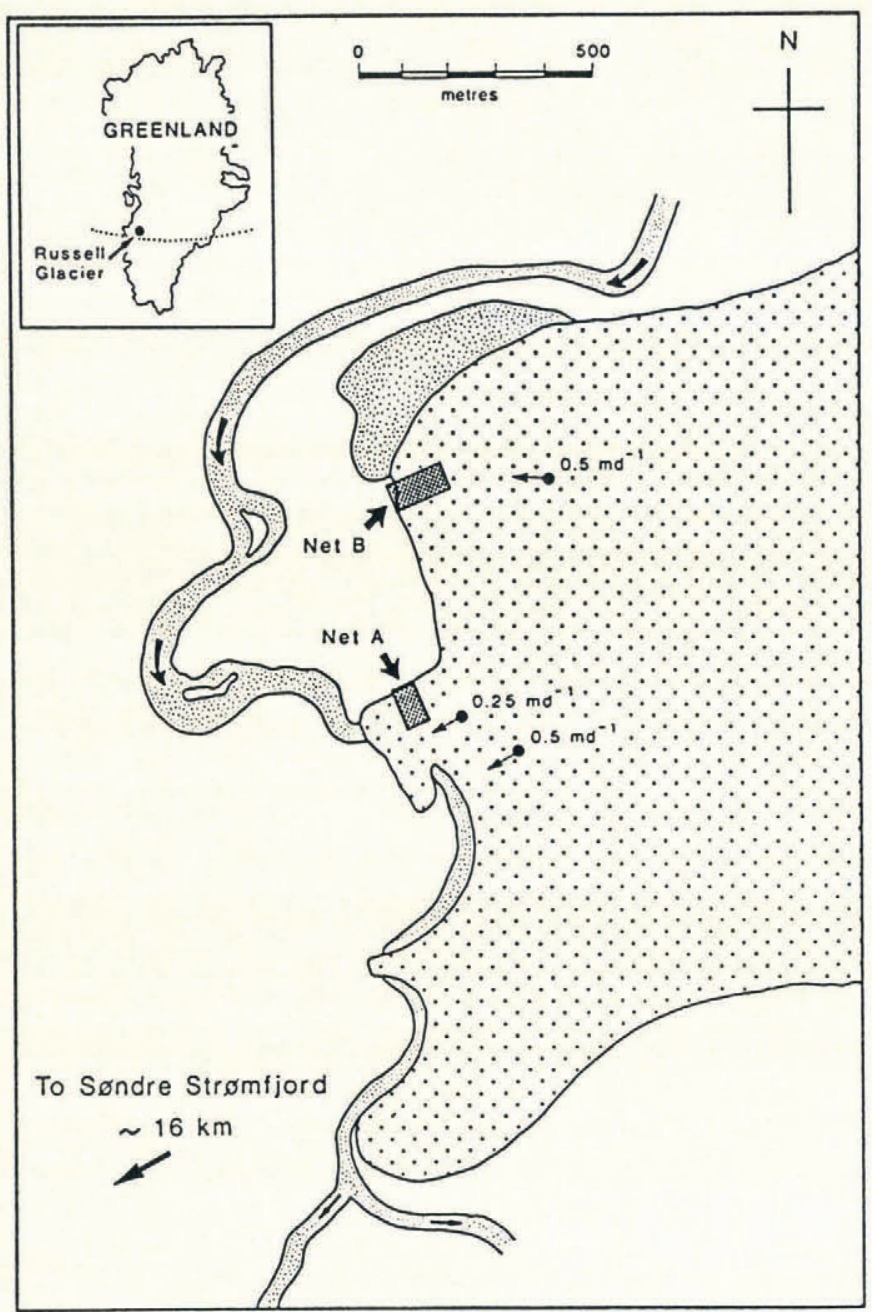

Fig. 1. The location of Russell Glacier in West Greenland and the position of strain nets $A$ and $B$ at the glacier snout. Figures beside arrows on the glacier surface represent measured ice velocities in September 1985. The coarse stipple is the glacier; the fine stipple is proglacial lakel stream.

currently re-advancing over a series of moraine ridges which were exposed or created during the 1920-60 retreat phase, and now stands at the position it last occupied between 1880 and 1920 (Fig. 2). The morphology of the ice margin and the topography of the ice surface depend in large part on the position of the ice front relative to the ridges across which it is passing. At the sites where strain measurements were carried out, there exists a subglacial moraine ridge within a few metres of, and approximately parallel to, the margin. These sites were specifically chosen as good test sites for small-area strain measurement, as the strain patterns in such an environment are likely to change over short distances. Velocity measurements which were made at the same time as the strain measurements indicate that the glacier is moving at rates in excess of $180 \mathrm{~m} \mathrm{a}^{-1}$ in its central part.

\section{FIELD MEASUREMENTS}

Two separate strain nets were established, designed to measure strain patterns at different types of margin. Net A, comprising 12 separate strain triangles, was located

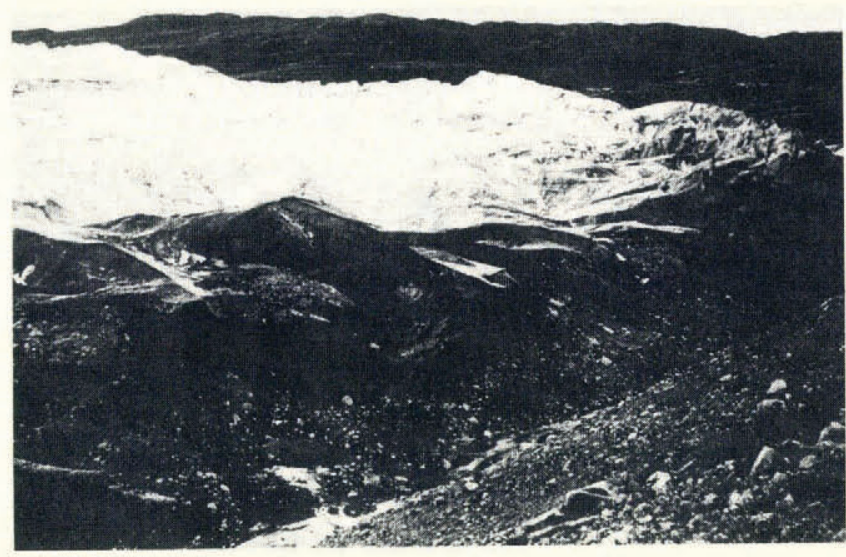

Fig. 2. Part of the ice margin in the vicinity of net $A$, showing ice flexure across moraine ridges.

perpendicular to a lateral margin of the glacier; net B, comprising 33 triangles, was perpendicular to a frontal margin. The positions of the two nets are shown in Figure 1. Each net consisted of an array of wooden stakes planted vertically into the ice surface. The distances between the stakes were measured by tape, with a repeatability of $0.25 \mathrm{~cm}$ on the smaller triangles and $1 \mathrm{~cm}$ on the larger triangles. The absolute positions of the nets were established by theodolite from a bedrock survey network at the glacier margin.

The nets were established at the beginning of September, and triangle sides were measured three times during the month: (1) when the net was established; (2)

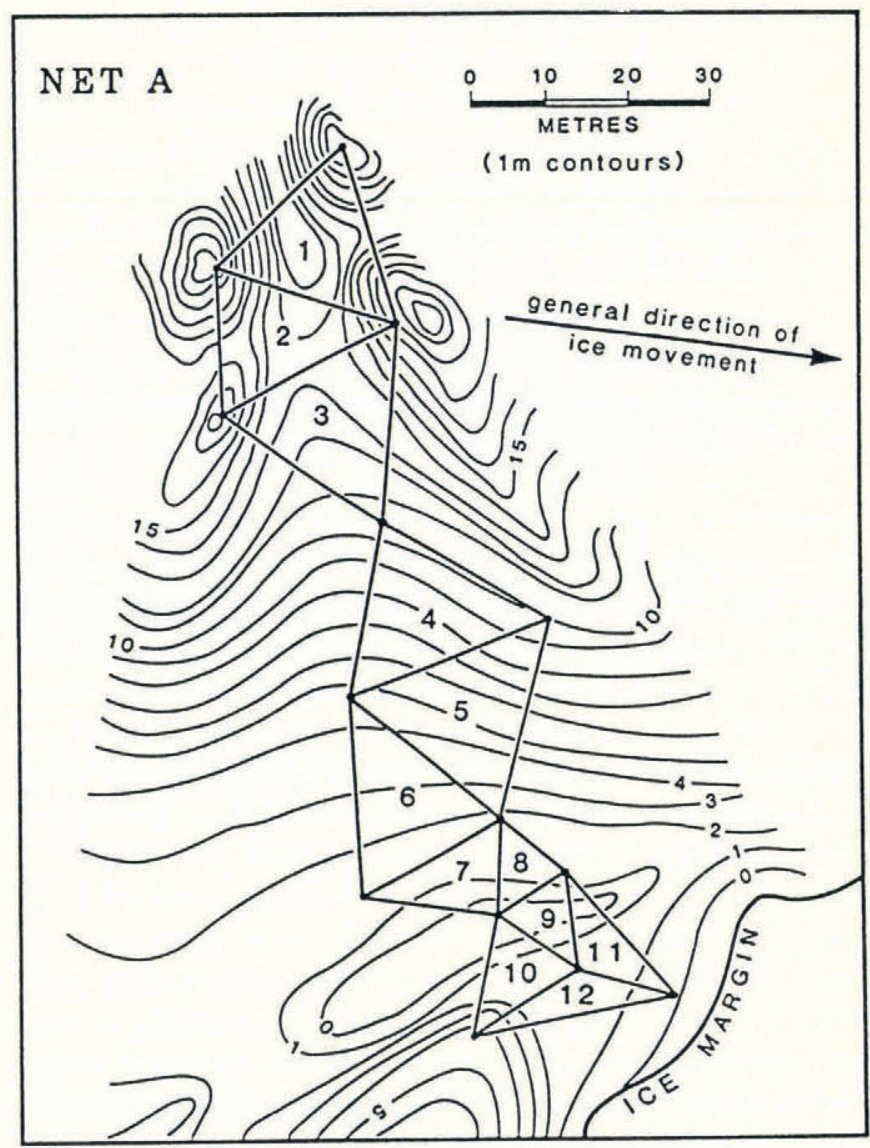

Fig. 3. Lay-out of strain net $A$, and the ice topography in that area. 


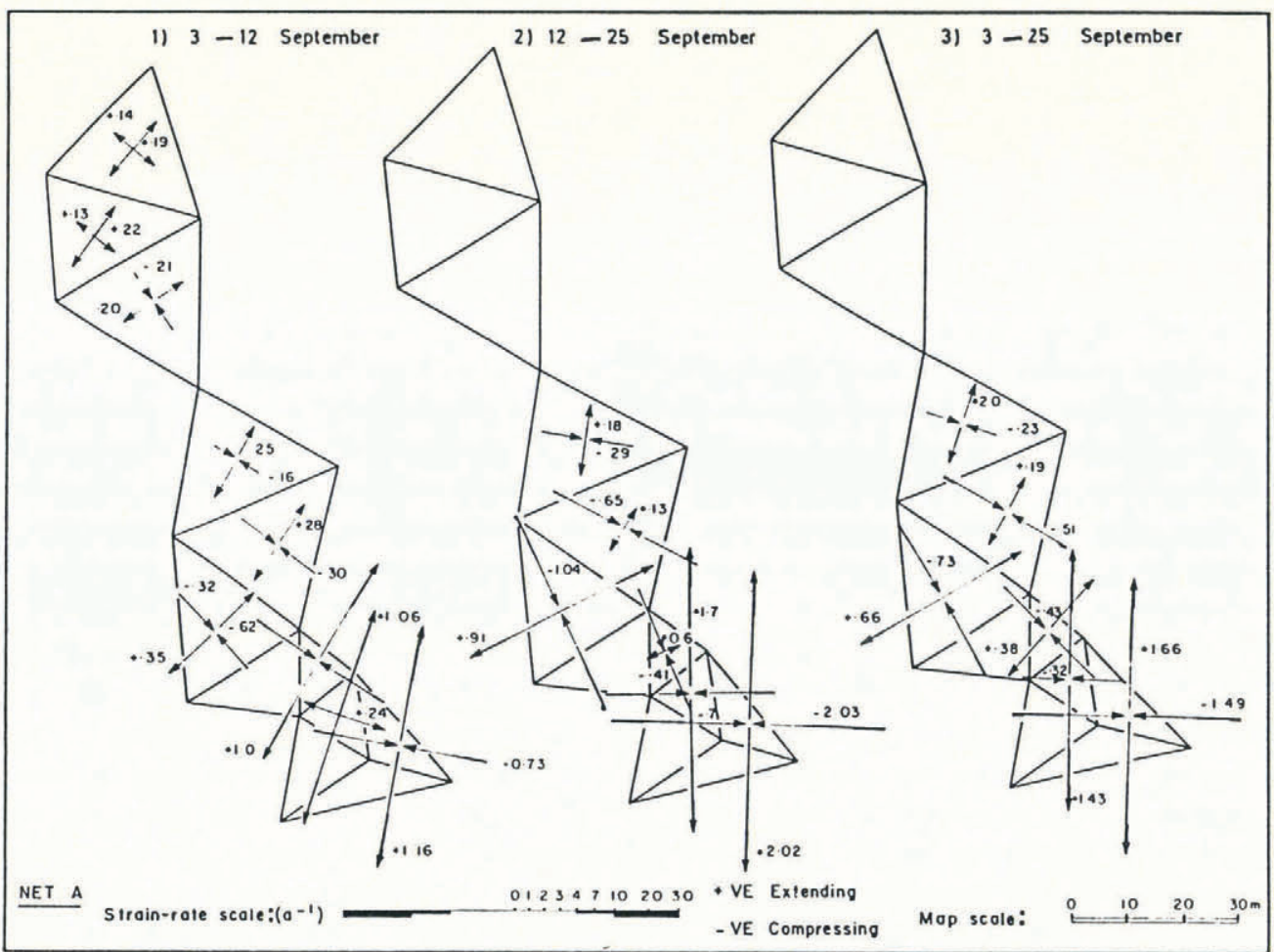

Fig. 4. Measured strain rates at net $A$.

after an interval of a few days; (3) after an interval of 2-3 weeks. The middle measurement was made so as to identify short-term variations and to check for errors in measurement.

\section{RESULTS}

\section{Net A}

\section{Introduction}

Triangle sides were measured on 3, 12 and 25 September, giving three sets of strain results, for periods of 9,13 and the aggregate of $22 \mathrm{~d}$. The $9 \mathrm{~d}$ results are available for all nine triangles, the $13 \mathrm{~d}$ and $22 \mathrm{~d}$ results for only six of them.

Figure 3 shows the form of the ice surface in the area of net A. Above the top of the net, the ice is heavily crevassed, and from an area of irregular topography at the top of the net the surface slopes down into a trough parallel to the margin, separated from the ice edge by a low ice rise about $25 \mathrm{~m}$ across. The trough and rise are probably caused by a moraine ridge recently and currently over-ridden by the ice. The ice edge itself is in the form of a slightly overhanging $2-3 \mathrm{~m}$ cliff, the ice flowing down the distal slope of one ridge of the overridden moraine complex.

Results

The three sets of strain results for net $\mathrm{A}$ are shown in Figure 4. With one exception (triangle 9), the orientation of the principal strains for each triangle is constant through the first and second periods. Strain magnitude, however, was not constant; again, with one exception (triangle 8 ), the compressive strain rates were consistently greater during the second period than the first. The scale of this increase is greatest near the margin and decreases steadily up-net (Table 1).

Table 1. Change in compressive strain rates during September 1985

$\begin{array}{ccc}\text { Triangles with } & \text { Principal compressive } & \text { Principal compressive } \\ \text { negative } & \text { strain rate }\left(a^{-1}\right) & \text { strain rate }\left(a^{-1}\right) \\ \text { strain rates } & 3-12 \text { September } & 12-25 \text { September }\end{array}$

\section{NET A}

$\begin{array}{ll}-0.16 & -0.29 \\ -0.30 & -0.65 \\ -0.32 & -1.04 \\ -0.62 & -0.41 \\ -0.73 & -2.03\end{array}$

\section{NET B}

$\begin{array}{ccc}6 & -0.17 & -0.70 \\ 7 & -1.10 & -0.60 \\ 8 & -0.37 & -4.00 \\ 9 & -0.18 & -0.61 \\ 10 & -0.17 & -0.56 \\ 11 & -0.04 & -0.50 \\ 13 & -0.09 & +0.09 \\ 14 & -1.58 & -2.48 \\ 16 & -0.32 & -0.46 \\ 29 & -0.71 & -0.39\end{array}$


At the top of the net, principal shear strain (which is measured at $45^{\circ}$ clockwise from the principal positive strain) is at about $41^{\circ}$ towards the margin, approximately parallel to flow. With the single exception of triangle 8, the shear strain rate increases steadily towards the margin. The principal compressive and extending strain rates also increase towards the margin. In the triangles most distant from the margin there is no compressive element in the strain, while at the margin it reaches values in excess of $-2 \mathrm{a}^{-1}$. Compressive strain acts perpendicular to or at up to $45^{\circ}$ to the margin, while extending strain acts parallel to or at up to $135^{\circ}$ to the margin.

Changes in triangle area are less constant through time (Table 2). Of the six triangles that have complete sets of readings, only two show consistency in area change through time. Considering the longest available aggregate for each triangle, those in the middle of the net show decreases in area, while those at the top and at the bottom show overall increases. However, in all six cases, the rate of surface-area change is lower (i.e. tending more towards compression) in the second part of the month than in the first (Table 1, final column). These measured strain values are reflected in surface forms such as crevasses on the glacier, with crevasses in the marginal zone being approximately normal to the principal extending strain and to the margin. Above the top of the net, where

Table 2. Change in rate of surface-area change during September 1985

\section{Triangle Rate of surface- Rate of surface- Change in rate No. area change $\left(a^{-1}\right)$ area change $\left(a^{-1}\right)$ between periods 3-12 September 12-25 September}

NET A

$\begin{array}{cccc}4 & +0.09 & -0.12 & -0.21 \\ 5 & -0.02 & -0.51 & -0.49 \\ 6 & +0.03 & -0.13 & -0.16 \\ 8 & +0.39 & -0.35 & -0.74 \\ 9 & +1.32 & +0.99 & -0.33 \\ 11 & +0.44 & -0.01 & -0.45\end{array}$

\section{NET B}

$\begin{array}{cccc}1 & -0.24 & -0.38 & -0.14 \\ 2 & +0.12 & -0.18 & -0.30 \\ 3 & +0.15 & -0.22 & -0.37 \\ 5 & -0.05 & -0.08 & -0.03 \\ 6 & +1.56 & -0.61 & -2.17 \\ 7 & +0.23 & -0.003 & -0.23 \\ 8 & +3.25 & -3.25 & -6.50 \\ 9 & +0.16 & +0.03 & -0.13 \\ 11 & +0.43 & -0.35 & -0.78 \\ 13 & +0.42 & +0.27 & -0.15 \\ 15 & -1.18 & -2.48 & -1.30 \\ 16 & +0.02 & +0.09 & +0.07 \\ 29 & -0.57 & -0.01 & +0.56\end{array}$

extending strain probably predominates in all directions, crevassing is less uni-directional.

\section{Net B}

\section{Introduction}

Triangle sides on net B were measured on 9, 13 and 25 September, giving strain results for periods of 4,12 and an aggregate $16 \mathrm{~d}$. The topography of the area surrounding the net is shown on Figure 5. At the margin, the ice forms a convex ramp and is over-riding a low moraine ridge complex. The margin-parallel ice ridge and trough presented here are slightly less pronounced than at net A.

\section{Results}

The three sets of strain results for net B are shown in Figure 6. Strain magnitudes and orientations are much less consistent between the two periods at net B than at net A. The strain pattern is in some cases partly or completely reversed between the first and second periods (e.g. triangles 8, 6, 29 and 2) and in others shows large variations in strain magnitude. There is not a pattern of change through time as clear as that measured at net $\mathrm{A}$, but consistency between adjacent triangles is good, even for the small triangles at the bottom of the net, and for the $4 \mathrm{~d}$ short period.

Strain rates are lowest at the greatest distance from the margin (triangles 1,2 and 3), increase towards the margin, and peak about $20 \mathrm{~m}$ from the edge (triangle 8 ).

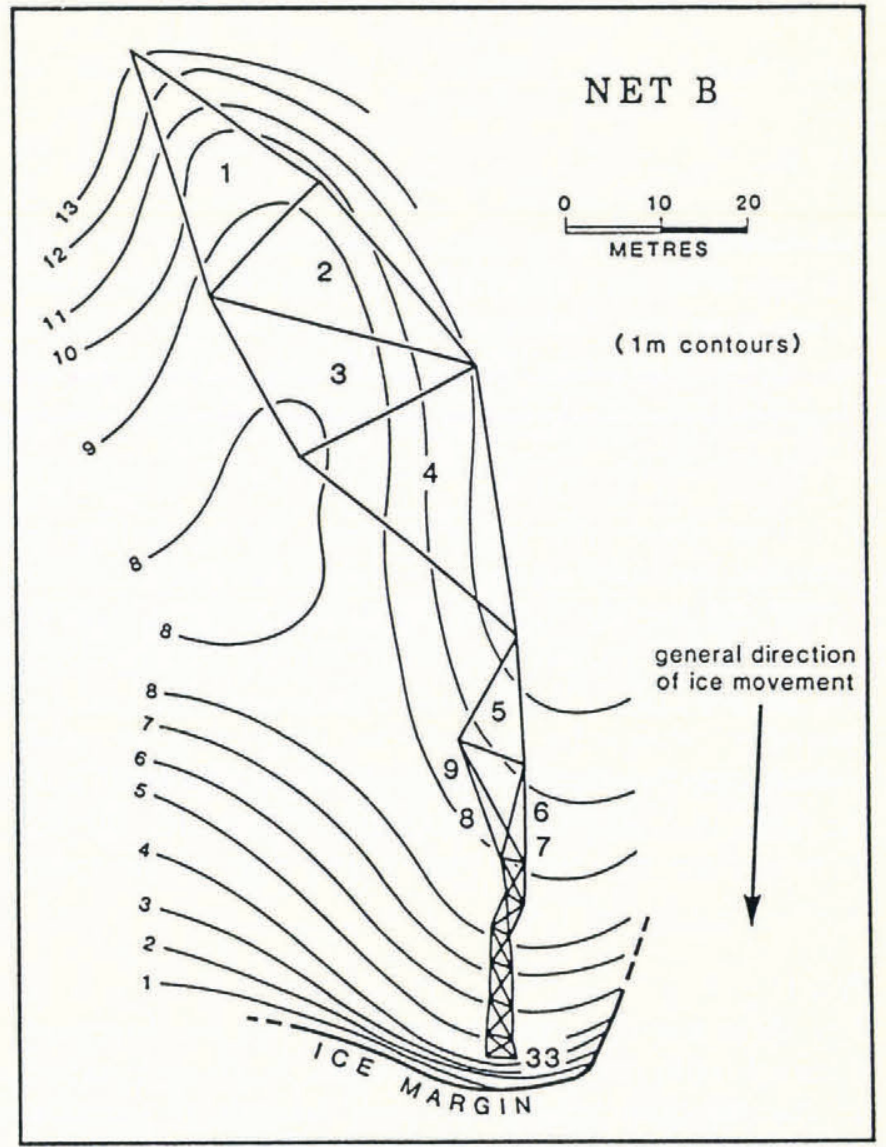

Fig. 5. Lay-out of strain net B, and the ice topography in that area. 


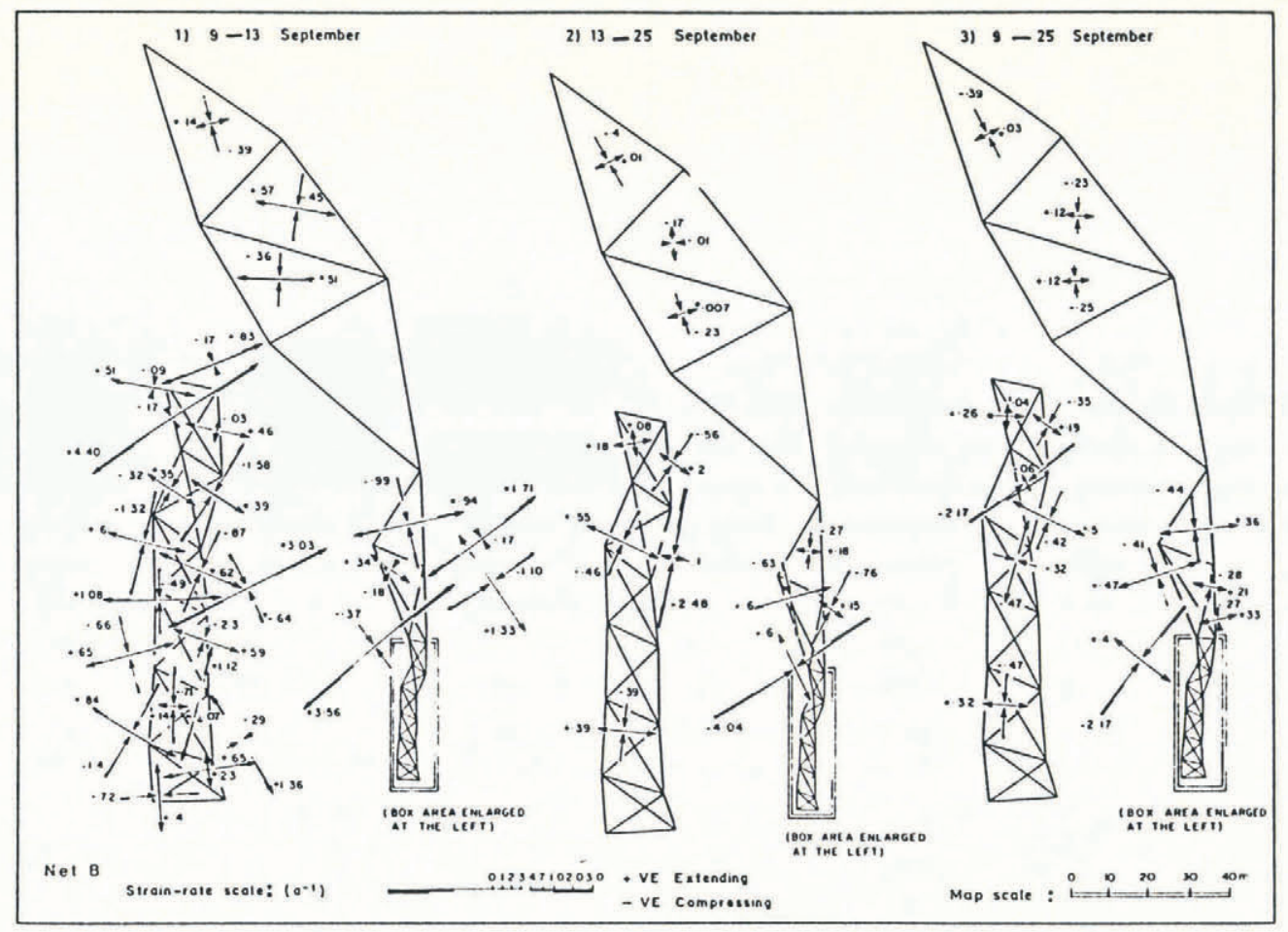

Fig. 6. Measured strain rates at net $B$.

Within 5-10 $\mathrm{m}$ of the margin during the $4 \mathrm{~d}$ period, strain perpendicular to the margin was positive (extending) and strain parallel to the margin was negative (compressive). Beyond this extreme marginal zone, the opposite was true, with compressive strain roughly perpendicular to the margin, although the observations are a little variable in the middle sections of the net. The available 12 and $16 \mathrm{~d}$ results suggest that during the major part of the study period compressive flow perpendicular to the margin extended even closer to the edge (triangle 29) (Table 2).

Changes in triangle area are variable across the two time sets and between adjacent triangles (Table 2). Considering the aggregate $16 \mathrm{~d}$ values, the top end of the net is experiencing general compression to within $30 \mathrm{~m}$ of the margin. In the marginal $30 \mathrm{~m}$, values vary massively even between partly overlapping, very small, triangles. The $4 \mathrm{~d}$ values are even more variable.

Between September 1985 and April 1986, one triangle survived intact (triangle 1). The $189 \mathrm{~d}$ through-winter strain value is similar to the values measured in September. At the bottom of the net no complete triangles survived, but the poles which did survive indicate considerable compression and steepening of the marginal ramp during the winter (Fig. 7).

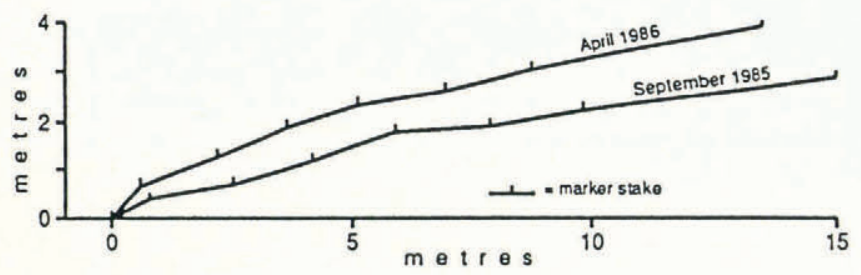

Fig. 7. Cross-sections of the ice margin at net B in September 1985 and April 1986, demonstrating a change in form over the winter.

\section{DISCUSSION AND IMPLICATIONS}

Surface strain rates reflect ice-flow dynamics and the effect of external factors at the margin. The interplay between these forces is marked by increasing strain rates and the development of strong compressive strain close to the margin.

In net $\mathrm{A}$ the deceleration of ice near the lateral margin leads to the development of extremely high shear strain parallel to the margin as well as high compressive strain at $45^{\circ}$ to the margin. At net B, flow directly towards the margin results in compressive strain roughly perpendicular to the margin. This extends further up-glacier than the compressive strain generated at the lateral margin at net A. In both cases, moraine ridges beneath the ice present an additional obstacle to flow, and compressive strain is highest just up-flow of the obstacle. This may be due to the overall blocking effect of the moraine, or to bending upward of the ice as it reaches the proximal slope of the ridge. If the latter is true, compression will not necessarily extend to the bed, and surface compression may be matched by basal extension, possibly involving the opening of basal crevasses. The great variability in strain rates over short areas in the middle of net $\mathrm{B}$ may be related to the variability of subglacial moraine topography.

At net $\mathrm{A}$, the thin carapace of ice overtopping the ridge becomes increasingly independent of the downvalley flow, and strong shear develops between the two. The orientations of the principal strains change, and cambering of the ice leads to surface extension (positive strain) across the ridge crest (triangle All), possibly matched by basal compression. The surface extension is as clearly evident in the crevasse pattern as in the strain data. Down-flow from the subglacial ridge, the ice impacts the moraine and strains are again compressive.

The extent of marginal retardation increases as the 
season progresses, the temperature falls and the marginal zone freezes. This is illustrated by the increase in strain between periods (i) and (ii) at net A (Table 1) and by the changing form of the ice margin (Fig. 7).

At the top of net B (triangle 1), winter strain is similar to that measured in the autumn. This may be because the frozen surface of the proglacial lake is less of an obstacle to flow than frozen moraine ridges, or may reflect the upglacier penetration of flow effects from the extreme margin. At net A, and at the bottom of net B, away from the lake, steepening of the margin coupled with the much less significant advance, than at the lake site, implies stronger winter compression over most of the area than the triangle 1 data show. This may be because triangle 1 is some distance from the front and lies outside the extreme marginal compressive zone. The winter increase may be due either to the winter cold wave and marginal freezing to the bed or to the net forward movement of the glacier, during the winter period of reduced ablation, coupled with the retarding impact of the marginal moraine ridge.

\section{CONGLUSIONS}

Away from the margin of the glacier, strain rates are low and positive (extending) strain predominates. Strain rates increase markedly toward the margin, and close to the margin negative (compressive) strain becomes increasingly important. Strain rates close to the margin reflect pro- and subglacial topography, and the orientation of the margin relative to the direction of the flow; negative (compressive) strain extends further up-glacier from a frontal margin than from a lateral margin. Strain rates close to the margin increase through the autumn period and are high during the winter.

By using strain triangles much smaller than those which have commonly been described in earlier literature, it may be possible to isolate the separate parameters which control the surface strain rate. For example, identifying variation in strain rate at the scale of metres, rather than tens of metres, makes it possible to recognize the separate influences of marginal retardation and flexing of ice over subglacial obstructions very close to the margin.

\section{ACKNOWLEDGEMENTS}

When these measurements were made, the author was in receipt of a U.K. NERC Studentship at the University of Aberdeen, supervised by D.E. Sugden and C. M. Clapperton. Their help and support is gratefully acknowledged.

\section{REFERENCES}

Gemmell, J.C. 1985. The origin, composition, and behaviour of basal ice at Nigardsbreen, Norway. (Ph.D. thesis, University of Aberdeen.)

Hambrey, M.J. and F. Müller. 1978. Structures and ice deformation in the White Glacier, Axel Heiberg Island, Northwest Territories, Canada. 7. Glaciol., 20(82), 4166.

Hambrey, M.J., A. G. Milnes and H. Siegenthaler. 1980. Dynamics and structure of Griesgletscher, Switzerland. 7. Glaciol., 25(92), 215-228.

MacAyeal, D. R. 1985. Optimal measurement of ice-sheet deformation from surface-marker arrays. 7. Glaciol., 31 (107), 54-59.

Meier, M. F. 1960. Mode of flow of Saskatchewan Glacier, Alberta, Canada. U.S. Geol. Surv. Prof. Pap. 351.

Nye, J.F. 1959. A method of determining the strain-rate tensor at the surface of a glacier. J. Glaciol., 3(25), 409419.

Ramsay, J.G. 1967. Folding and fracturing of rocks. New York, McGraw-Hill.

Williams, L.D. and P. G. Knight. 1987a. A computer program for glacier-surface plain-strain analysis. Aberdeen, University of Aberdeen. Department of Geography. (Discussion Paper 10.)

Williams, L. D. and P. G. Knight. 1987b. Correspondence. A computer program for glacier-surface plain-strain analysis. F. Glaciol., 33(114), 249-250.

The accuracy of references in the text and in this list is the responsibility of the author, to whom queries should be addressed. 